\title{
LETTERS
}

\section{Additional safety consideration for azithromycin in the management of SARS-CoV-2 infection}

David Juurlink's timely and otherwise thorough review of chloroquine, hydroxychloroquine and azithromycin ${ }^{1}$ omitted an important safety consideration for azithromycin that is relevant to recipients of allogeneic blood and marrow transplantation, in whom azithromycin may be prescribed to prevent or treat transplantrelated lung disease (especially bronchiolitis obliterans). In a 2017 randomized controlled trial involving participants receiving blood and marrow transplants, those assigned to receive prophylactic azithromycin had significantly higher relapse rates for their underlying hematologic malignant disease, as well as an increase in overall mortality. ${ }^{2}$

In 2018, this serious safety concern led Health Canada to warn prescribers and patients about the use of azithromycin in recipients of blood and marrow transplants. ${ }^{3}$ Because these recipients are often profoundly immune suppressed,-infection with severe acute respiratory syndrome coronavirus 2 (SARS-CoV-2) may be more common and severe. Prescribers should thus be cognizant of this potentially serious adverse effect of azithromycin in this particular group of patients.

\section{Matthew D. Seftel MBChB MPH}

Hematologist, University of British

Columbia, Vancouver, BC

- Cite as: CMAJ 2020 May 4;192:E483. doi: 10.1503/cmaj. 75427

\section{References}

1. Juurlink DN. Safety considerations with chloroquine, hydroxychloroquine and azithromycin in the management of SARS-CoV-2 infection. CMAJ 2020 Apr. 8 [Epub ahead of print]. doi:10.1503/ cmaj.200528.

2. Bergeron A, Chevret S, Granata A, et al. Effect of azithromycin on airflow decline-free survival after allogeneic hematopoietic stem cell transplant: The ALLOZITHRO randomized clinical trial. JAMA 2017;318:557-66.

3. Health Canada warns Canadians of new safety information related to long-term use of azithromycin following stem cell transplants in cancer treatment. Ottawa: Government of Canada; 2018. Available: https://healthycanadians.gc.ca/ recall-alert-rappel-avis/hc-sc/2018/67430a-eng. php (accessed 2020 Apr. 8).

Competing interests: None declared. 